\title{
Scarf Repair of Composite Laminates
}

\author{
Zonghong Xie ${ }^{1}$, Xiang $\mathrm{Li}^{1, \mathrm{a}}$ and Qun $\mathrm{Yan}^{2}$ \\ ${ }^{1}$ Northwestern Polytechnical University, Department of Aerospace Design Engineering, 710072 Xi'an, China \\ ${ }^{2}$ Shenyang Aircraft Design \& Research Institute, 110000 Shenyang, China
}

\begin{abstract}
The use of composite materials, such as carbon-fiber reinforced plastic (CFRP) composites, aerostructures has led to an increased need of advanced assembly joining and repair technologies. Adhesive bonded repairs as an alternative to recover full or part of initial strength were investigated. Tests were conducted with the objective of evaluating the effectiveness of techniques used for repairing damage fiber reinforced laminated composites. Failure loads and failure modes were generated and compared with the following parameters: scarf angles, roughness of grind tool and number of external plies. Results showed that scarf angle was the critical parameter and the largest tensile strength was observed with the smallest scarf angle. Besides, the use of external plies at the outer surface could not increase the repairs efficiency for large scarf angle. Preparing the repair surfaces by sanding them with a sander ranging from 60 to 100 grit number had significant effect on the failure load. These results allowed the proposal of design principles for repairing CFRP structures.
\end{abstract}

\section{Introduction}

Adhesively bonded scarf repairs provide a significant recovery of residual strength in damaged composite structure and are compared with external patch repairs, and scarf repairs have relatively high level to minimize aerodynamic disturbance[1]. For highly loaded advanced composite structures, scarf angles ranging from 20:1 to $60: 1$ are often required to restore a damaged structure to its as-designed ultimate strength.

The restore efficiency are affected by many parameters, typically including surface preparing, scarf angles and external plies. Harman and Wang [2] investigated the use of a low stiffness patch to repair carbon-fiber epoxy composites for scarf joint repairs. They found that a low stiffness patch improves the uniformity of adhesive stresses along the joint and consequently enhances the joint strength. Liu and Wang [3] used a 3D progressive damage model to investigate the effects of several repair parameters on the failure initiation strength, ultimate strength and failure mechanism of repaired open-hole composite plates in tensile tests. Their research showed that overlay thick patches will deteriorate the strength of the repaired structures. Campilho [4] investigated the tensile behavior of adhesive-bonded carbon/epoxy scarf repair using scarf angles ranging from $2^{\circ}$ to $45^{\circ}$. Two distinct failure modes were observed experimentally: type A and type B failures. Type A was observed for the repairs with $15^{\circ}$, $25^{\circ}$ and $45^{\circ}$ scarf angles, consisting of an entirely cohesive failure of the adhesive layer, which occurred abruptly without visible crack initiation. Type B failure occurred for the repairs with $2^{\circ}, 3^{\circ}, 6^{\circ}$ and $9^{\circ}$ scarf angles, consisting of cohesive and interlaminar/intralaminar failure. Kumar [5] investigated adhesively bonded aerospace composite scarf joints, with scarf angles ranging from $0^{\circ}$ to $5^{\circ}$, in uni-axial tension both experimentally and numerically. Results showed that fibre fracture and pull-out failure occurred for scarf angles less than about $2^{\circ}$ and cohesive shear failure of the adhesive occurred for scarf angles more than $2^{\circ}$. The knockdown in tensile strength was most prominent for scarf angles less than about $1^{\circ}$. Charalambides [6,7] and Pinto [8] investigated the use of over-laminating plies covering the repaired region at the outer or both repair surfaces as an attempt to increase the repairs efficiency. Sung[9] found that preparing the repair surface by sanding them with a diamond sander ranging from 60 to 400 grit number does not significantly affect failure load.

The current experiments for scarf repairs are designed to study these parameters on the repair performance. The tests were conducted at room temperature. The failure load and failure strength were used to evaluate the repair efficiency.

\section{Tensile experiment}

Plain weave carbon fiber fabric prepreg plies(with T700 fiber and CYCOM970 resin system) were used in the construction of the parent laminate and the repair patch. The mechanical properties were shown in Table 1.

The plates are manually scarfed to the required scarf angle using a die grinder having a detachable abrasive pad of \#60 grade and \#100 grade. The scarf surfaces prior the repair are cleaned.

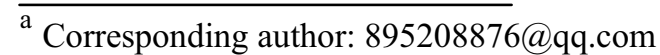


Two separate plates were joined together by the scarf techniques. Figure 1 shows the procedure sequence in the repair process of a damaged laminate.Initially a back plate was bonded at the back of the laminate in order to position the two parts. Then prepreg plies with tailored dimensions are placed on top of the plate. The patch materials are bonded to the laminate using adhesive film. Oneexternal plywas placed on the top and its boundaries are sealed with some adhesive. The electrically heated blanket is maintained until the reinforcement(patch) adherends to the parent component, awaiting solidification.

The manufacture process consisted of hand lay-up followed by curing in a hot-plates with 0.8 bar pressure. The heat cycle initiated warming up the plate at $2^{\circ} \mathrm{C} / \mathrm{min}$, followed by two hours curing at $180^{\circ} \mathrm{C}$. Cooling was performed at $3^{\circ} \mathrm{C} / \mathrm{min}$ up to room temperature (Figure 2).

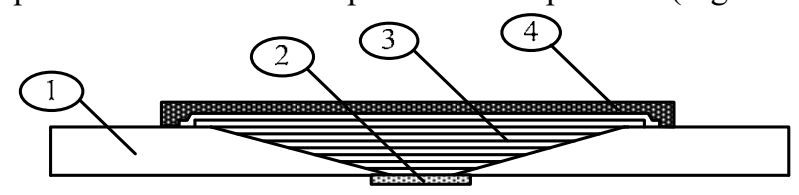

1. Parent Component

2. Back Patch

3. Repair Ply

4. Vacuum Bag

Figure 1. Schematic of the vacuum patch repair process.

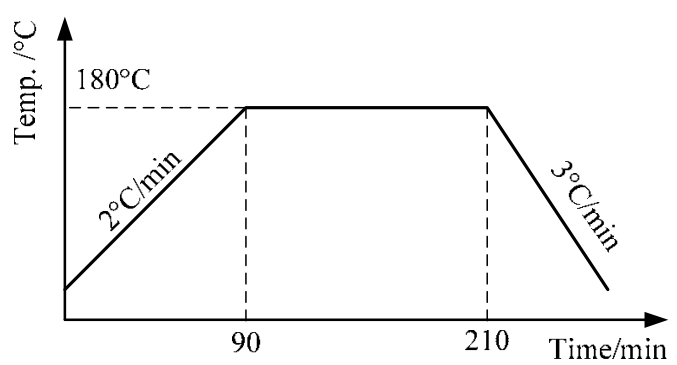

Figure 2. The temperature cycle used in making the repair.

The coupons are prepared by cutting the panel into the standard coupon sizes (ASTM D3039). The coupons dimensions were shown in Figure 3. Three different scarf angles were conducted, and $\alpha=2^{\circ}, 4^{\circ}$ and $6^{\circ}$. In order to investigate the external plies effect on the repair efficiency, two different laminates were designed with $\mathrm{N}=0$ and 1 . Besides, undamaged specimens, noted as scarf angle $\alpha=0^{\circ}$, were tested to verify the repairs recovery efficiency. A total of five specimens were tested in tension for each case described above. The complete test matrix was shown in Table 2.

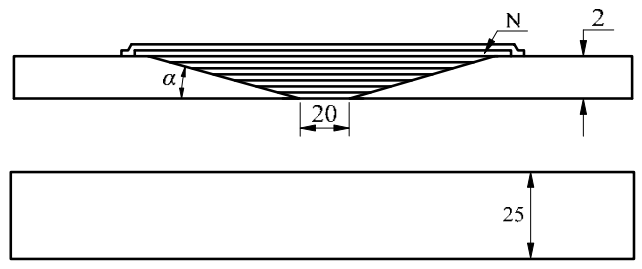

Figure3. Dimensions of the scarf repairs coupon.

The experiments were performed in a displacement control mode. All the specimens were loaded in tension until failure. Based on the failure load, the failure strength is calculated using Eq.(1).

$$
\sigma_{\max }=F_{\text {max }} /(W t)
$$

Strain gages were placed at several locations on the specimen as shown in Figure 4. The strain gage readings were used to analyze the damage initiation and damage growth path.

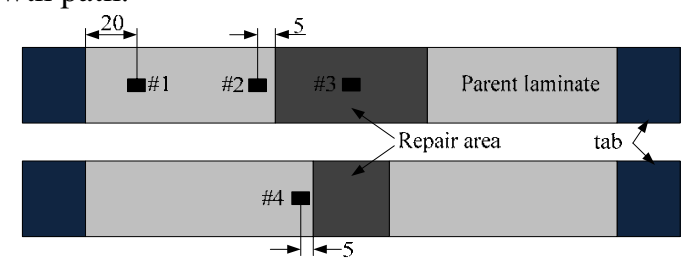

Figure 4. Strain gauge positions of the scarf joint coupon

Table 1. Mechanical properties of carbon-fiber/epoxy.

\begin{tabular}{|c|c|c|c|c|}
\hline $\mathrm{E} 1(\mathrm{GPa})$ & E2(GPa) & G12(GPa) & v12 & \\
\hline 54 & 54 & 13 & 0.044 & \\
\hline $\mathrm{Xt}(\mathrm{MPa})$ & $\mathrm{Xc}(\mathrm{MPa})$ & $\mathrm{Yt} \quad(\mathrm{MPa})$ & $\mathrm{Yc}(\mathrm{MPa})$ & $\mathrm{S}(\mathrm{MPa})$ \\
\hline 537 & 549 & 604 & 724 & 261 \\
\hline
\end{tabular}

\section{Test results of scarf repair specimens}

The load-displacement curves for the repaired specimens and undamaged specimens are shown in Figure 5. The repair specimens' stiffness reduces as the adhesive modulus is much lower than the parent laminate. Besides, stiffness reduction experienced by the repairs prior to failure was caused by the softening of the adhesive layer at the bond edges.

The strains measured at critical locations were shown in Figure 6. For the $6^{\circ}$ repair structure, the strain increase rate at location \#4 decreases with the load whilst it increases at location \#3 which indicates that the damage initiates from the bottom of the adhesive and grows along the bondline(see in Figure 7).

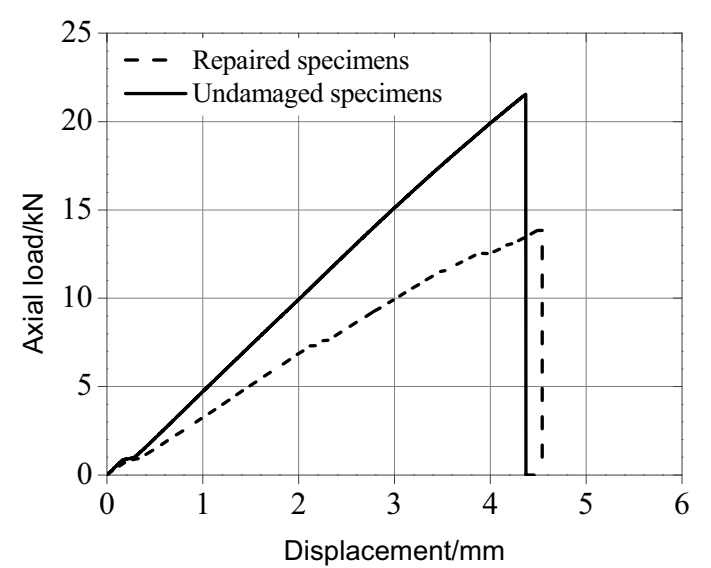

Figure 5. Typical load-displacement curvesof the specimens.

Figure 8 shows the typical damage modes observed in the tests conducted. For the case of $4^{\circ} \sim 6^{\circ}$ repair structure, it was seen that the primary damage mode is 
adhesive debond. However, for the case of $2^{\circ}$ repair structure, intra-laminar failure mode was also found.

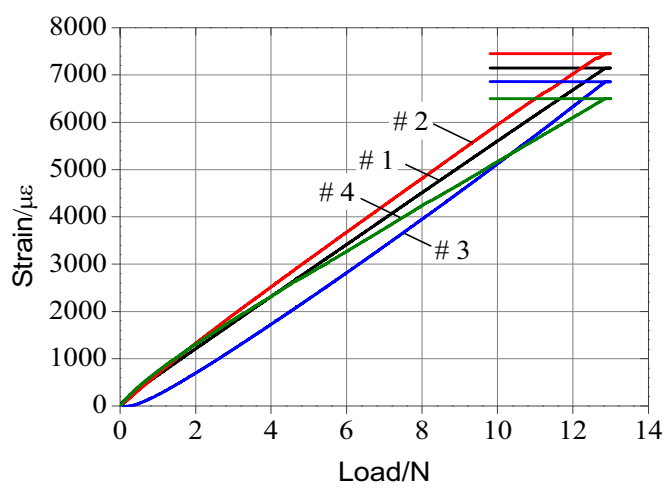

(a) $\alpha=2^{\circ}$

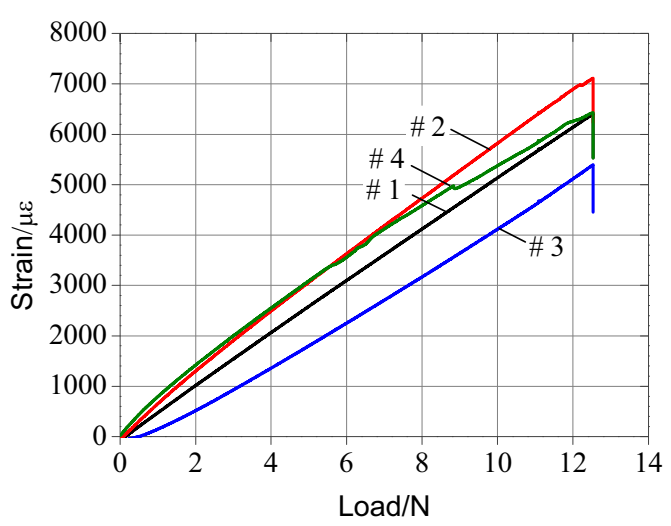

(b) $\alpha=4^{\circ}$

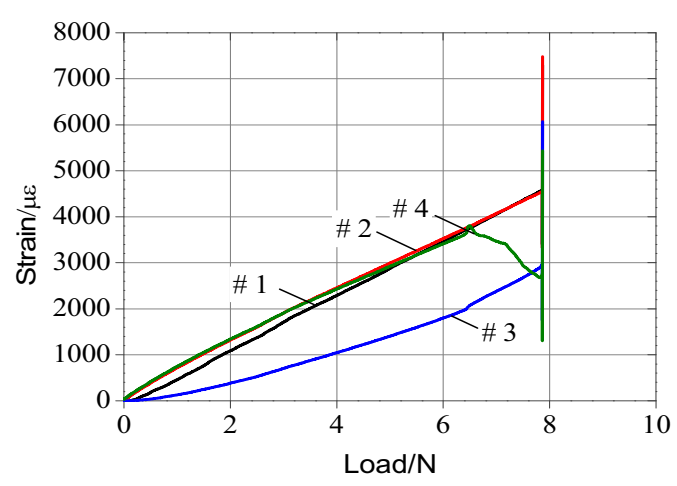

(c) $\alpha=6^{\circ}$

Figure 6. Strains measured at critical locations.

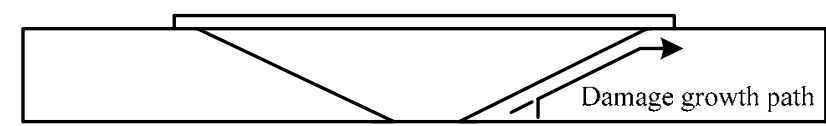

Figure 7. Damage initiation and growth path.

Figure 9 and Table 2 show the failure strength obtained from the scarf repair approach with different repair parameters. The failure strength of the parent material was approximately $455 \mathrm{MPa}$.

Testing of the scarf joints/repair recovered $29 \% \sim 62 \%$ of the parent laminate strength. The failure strength increases as the scarf angle decreases. A slight decreasing trend on failure strength was observed increasing the scarf angle, even though with some variations.

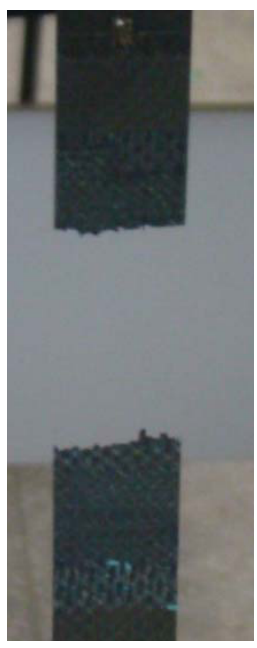

(a) $\alpha=2^{\circ}$

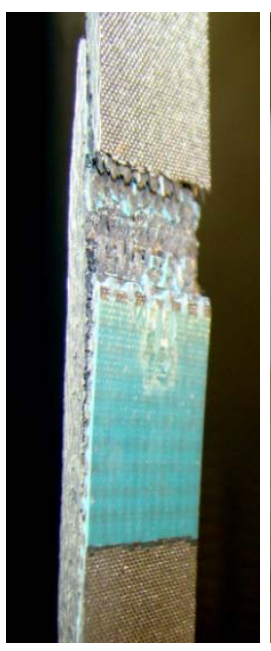

( b ) $\alpha=4^{\circ}$

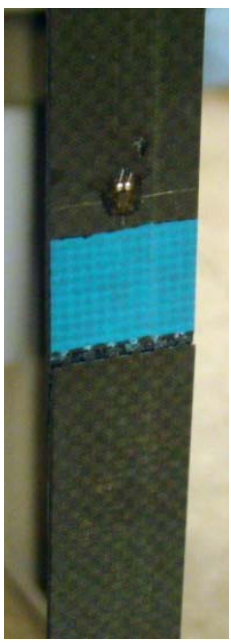

( c ) $\alpha=6^{\circ}$
Figure 8. Failure modes in repaired specimens.

Customarily, prior to repair the repair surface of the base laminate is sanded. To evaluate the influence of sanding on the failure load of repaired specimens, the repair surfaces were sanded with different grit diamond sanders. The failure loads of specimens repaired using different grit sanders are shown in Figure 9. The data indicate that the grit number of the sander have a significant effect on the failure load. For the material and type of repair used in this study, a sander with greater grit number could increase the failure strength for lager scarf angle and inverse trend was observed for small scarf angle.

The addition of external plies on the surface of the specimen resulted in decreased loads. The repair patch applied on one side contributes to out-of-plane bending by affecting the symmetry which resulted in secondary bending effects that begin to add the adhesive peel stress. However, reverse effect was observed in Sung's work [9]. This was because that in Sung's work, a smaller scarf angle was used. For the smaller values of $\alpha$, normal stresses, $\sigma_{\mathrm{n}}$, diminish in relative magnitude to $\tau_{\mathrm{avg}}$. Under these conditions, shear stresses, $\tau_{\mathrm{tn}}$, govern the repairs behavior [10].

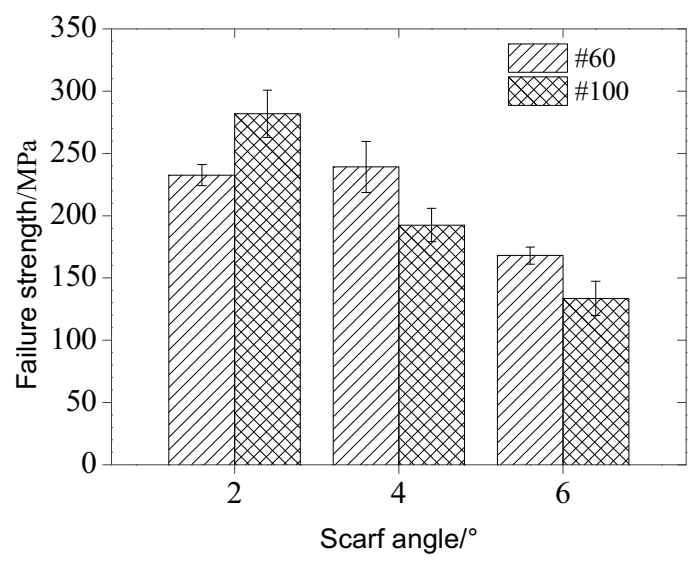

Figure 9. The failure strength of the specimens with different scarf angles and grit number of sanders. 
Table 2. Overview of the scarf joint specimens used in the tests.

\begin{tabular}{|l|l|l|l|}
\hline Scarf angle & Grit number & External plies & $\sigma_{\max } / \mathrm{MPa}$ \\
\hline $0^{\circ}$ & -- & -- & 455.1 \\
\hline \multirow{2}{*}{$2^{\circ}$} & $\# 60$ & 1 & 232.6 \\
\cline { 2 - 4 } & $\# 100$ & 1 & 281.8 \\
\hline \multirow{3}{*}{$4^{\circ}$} & $\# 60$ & 1 & 239.2 \\
\cline { 2 - 4 } & $\# 100$ & 1 & 192.4 \\
\hline \multirow{3}{*}{$6^{\circ}$} & $\# 60$ & 1 & 168.0 \\
\cline { 2 - 4 } & $\# 100$ & 1 & 133.6 \\
\cline { 2 - 4 } & $\# 100$ & 0 & 155.8 \\
\hline
\end{tabular}

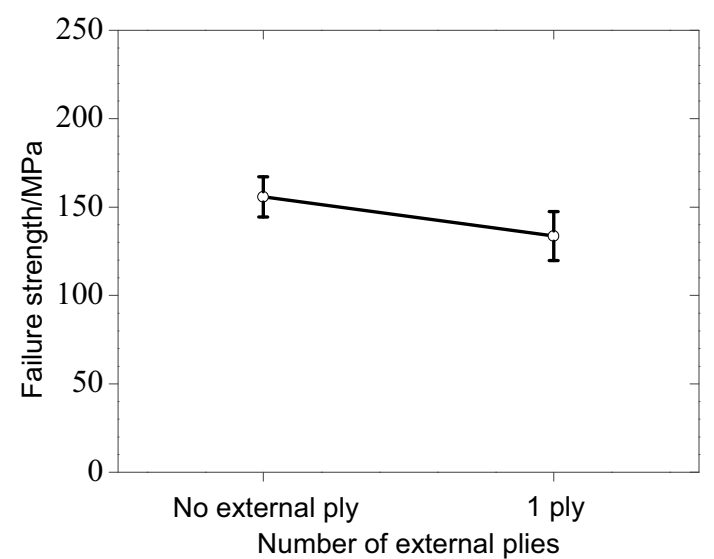

Figure 10. The effect of the number of external plies on the failure strength in scarf repairs.

\section{Conclusions}

The strength of scarf joints in composite structures has been thoroughly investigated. A series of scarf repair tests were performed to obtain their strength. The mechanical response and failure behavior of the specimens with different scarf angles and surface treatments method were evaluated via the comparison of experimental data. The experiment data shows that the optimal results are obtained from 2 degree using 1 layer for the external plies. The 2-degree repair results in intralaminar failure mode which is a higher strength failure mode. Repairs restored the strength to within $62 \%$ of the pristine panels. However, it should be noted that externalplies would reduce failure load for large scarf angle repairs as a result of secondary bending effect.

\section{Acknowledgements}

Project supported by National Natural Science Foundation of China (U1233202).

\section{References}

1. B. Whittingham, A.A. Baker, A. Harman, D. Bitton. Compos. Part A 40, 1419 (2009).

2. A.B. Harman, C.H. Wang. Compos. Struct. 75, 132, (2006).

3. X. Liu, G. Wang. Compos. Struct. 81, 331, (2007).
4. R.D.S.G. Campilho, M.F.S.F. de Moura, A.M.G. Pinto, J.J.L. Morais, J.J.M.S. Domingues. Compos. Part B. 40, 149 (2009).

5. S.B. Kumar, I. Sridhar, S. Sivashanker, S.O. Osiyemi, A. Bag. Mater. Sci. Eng. 132, 113 (2006).

6. M.N. Charalambides, R. Hardouin, A.J. Kinloch, F.L. Matthews. Compos. Part A. 29, 1371 (1998a)

7. M.N. Charalambides, R. Hardouin, A.J. Kinloch, F.L. Matthews. Compos. Part A. 29, 1383 (1998b)

8. A.M.G. Pinto, R.D.S.G. Campilho, M.F.S.F. de Moura, I.R. Mendes. Int. J. Adhes. Adhes. 30, 329, (2010).

9. H.A. Sung, G.S. Springer. J. Compos. Mater. 32, 11 (1998).

10. R.D.S.G. Campilho, M.F.S.F. de Moura, J.J.M.S. Domingues. J. Adhes. Sci. Technol. 21, 855 (2007). 